\title{
THE ZINC MEDIATED CONDENSATION OF AMINO ACID ESTERS WITH IMINES TO $\beta$-LACTAMS
}

\author{
Johann T.B.H. Jastrzebski and Gerard van Koten ${ }^{*}$ \\ Debye Institute, Department of Metal-Mediated Synthesis, \\ Utrecht University, Padualaan 8, 3584 CH Utrecht, The Netherlands.
}

(Received 1 April 1993)

\begin{abstract}
An experimentally attractive stereoselective 'one pot' synthesis of $\beta$-lactams is described. This route is based on the zinc mediated condensation of an $\alpha$-amino acid ester with an imine via a zinc ester enolate. Making use of proper substituents in both the amino acid ester and the imine the stereochemistry of the $\mathrm{C}-\mathrm{C}$ bond forming step can be completely controlled.
\end{abstract}

\section{Introduction}

The principal building-block of natural and synthetic $\beta$-lactam antibiotics, of which the most important ones are schematically shown in Figure 1, consists of a four-membered cyclic amide (2-azetidinone). It is especially the stereochemical arrangement (cis or trans) of the substituents present at the 3- and 4-position of the fourmembered ring and the absolute stereochemistry of the respective chiral centers in the molecule which control the biological activity of these compounds. For some of these antibiotics to be biologically active a cis arrangement of the substituents at the four-membered ring is required, for example as in 1, 2 and 6, while for other compounds a trans arrangement as in $\mathbf{3}$ and $\mathbf{5}$ is necessary (see Figure 1). Therefore much effort has been spent in developing diastereoselective synthetic routes to substituted 2-azetidinones as precursors for known and new $\beta$-lactam antibiotics.<smiles>CC1(C)S[C@@H]2[C@H](NC=O)C(=O)N2[C@H]1C(=O)O</smiles>

1 Penicillin (natural, 1929)<smiles>O=CN[C@H]1CN([C@H](C(=O)O)c2ccc(O)cc2)C1=O</smiles>

4 Nocardicin (natural, 1976)<smiles>CC(=O)OCC1=C(C(=O)O)N2C(=O)[C@H](NC=O)[C@H]2SC1</smiles>

2 Cephalosporin (natural, 1945)<smiles>[CH][C@H]1[C@@H](NC(=O)/C(=N/OC(C)(C)C(=O)O)c2csc([NH3+])n2)C(=O)N1S(=O)(=O)O</smiles>

5 Aztreonam (synthetic, 1981)<smiles>C[C@@H](O)[C@H]1C(=O)N2C(C(=O)[O-])=C(SCC[NH3+])C[C@H]12</smiles>

3 Thienamycin (natural, 1976)<smiles>CS(=O)(=O)N1C(=O)[C@@H](NC(=O)/C(=N\OCC(=O)O)c2csc(N)n2)[C@@H]1COC(N)=O</smiles>

6 Carumonam (synthetic, 1982)

Figure 1. Some of the important classes of $\beta$-lactam antibiotics.

The first representative of the 2-azetidinones was synthesized by Staudinger in $1907 .{ }^{1}$ However, it was not until the discovery of penicillin and its antibacterial properties by Fleming ${ }^{2}$ in 1929 that extensive studies to the synthesis of this class of compounds started. Nowadays thousands of compounds containing the $\beta$-lactam ring have been either isolated from natural sources or synthesized. ${ }^{3-6}$ Among many synthetic approaches for the 
construction of the $\beta$-lactam ring, the two main routes are: $i$, the Staudinger-cycloaddition reaction of a (in situ generated) ketene with an imine, and $i i$, the condensation reaction of a metal ester enolate with an imine and subsequent intramolecular ring closure, schematically shown in eqns. 1 and 2, respectively (for excellent reviews see refs 7-12).

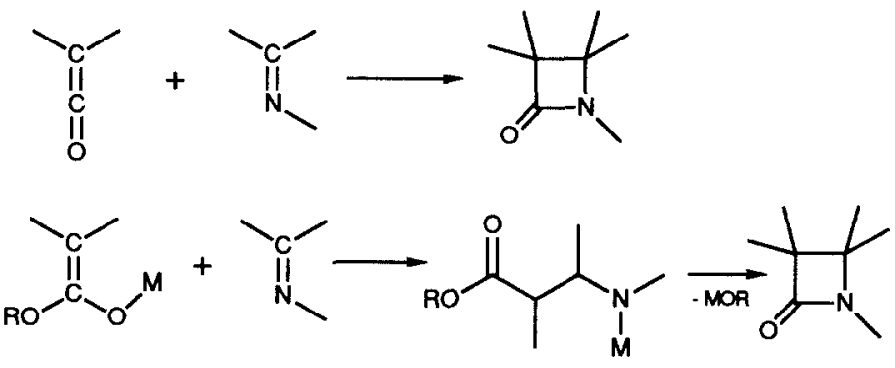

A major disadvantage of the first reaction (1) is that usually a mixture of all of the possible stereoisomers is formed. In this respect it should be noted that recently a few examples of highly stereoselective routes based on the ketene / imine cycloaddition have been reported. The first example of the latter reaction (2) is the condensation of Reformatsky reagents (i.e. zinc ester enolates) with simple imines to $\beta$-lactams reported by Gilman and Speeter. ${ }^{13}$ The modern enolate chemistry is now standard for organic chemists and many routes to known and new $\beta$-lactams have been developed based on the enolate imine condensation reaction. ${ }^{7-12}$ Most likely as a consequence of a better defined transition-state in these type of reactions, compared to the Staudinger reaction, complete control over regio- and diastereo- and enantioselectivity is possible. ${ }^{7-11}$

Our own effort in the field of $\beta$-lactam synthesis started with the serendipitous discovery during our studies of the reactions of alkyl-zinc and -aluminum compounds with 1,4-dihetero-1,3-butadienes ${ }^{14-16}$ that the reaction of an $\alpha$-iminoester with diethylzinc afforded a trans- $\beta$-lactam in quantitative yield, ${ }^{17}$ eqn. 3 .

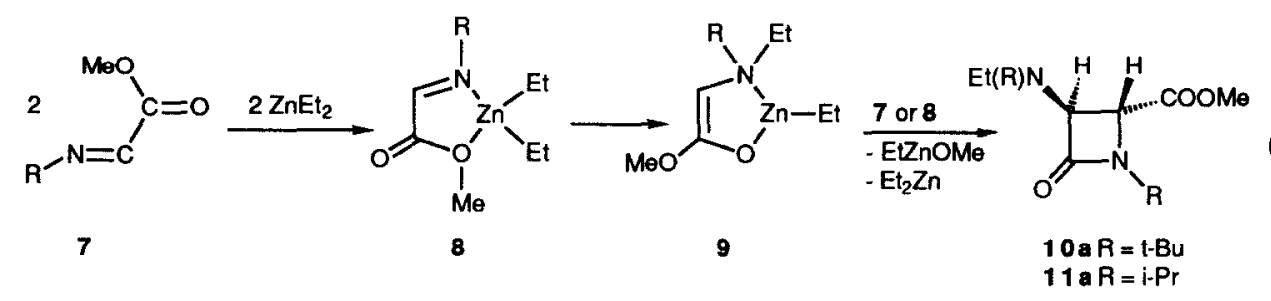

The initial step in this reaction is the formation of a donor-acceptor complex 8 between diethylzinc and the $\alpha$-iminoester followed by a process involving the selective transfer of an ethyl radical, which is formed via prior single electron transfer in complex $8,15,18$ to the (imino) $N$ atom resulting in the formation of the ethylzinc $\beta$-amino ester enolate 9. This enolate undergoes an aldol-like condensation reaction with the imine functionality in either the $\alpha$-iminoester 7 or its diethylzinc complex 8 . Finally, the $\beta$-lactam 10 is formed as a result of intramolecular ring-closure. That it is most likely the diethylzinc complex $\mathbf{8}$, and not the $\alpha$-iminoester itself which undergoes the reaction with the zinc ester enolate 9 became evident during a recent study to the reactivity of zinc ester enolates towards imines derived from phenylglycine, $c f$. eqn. 5 . Unfortunately, as a consequence of the properties of the starting materials, the reaction described above affords $\beta$-lactams bearing alkyl substituents on both nitrogen atoms, which can not be easily removed and thus prevents a route to further functionalization. Furthermore, the number of easily accessible $\alpha$-iminoesters is rather limited. Therefore a detailed study of the reaction of independently prepared zinc ester enolates (obtained via transmetalation of lithium enolates) with imines was started by our group. 
Synthesis of 3-amino-2-azetidinones via the zinc mediated condensation of $N, N$-disubstituted glycine esters with imines.

Deprotonation of $N, N$-diethylglycine ethyl ester with LDA (lithium diisopropylamide) and successive transmetallation with $\mathrm{EtZnCl}$ or $\mathrm{ZnCl}_{2}$ affords after work-up the ethyl- and chlorozinc enolates 12a and 12b, respectively (see eqn.4) as white microcrystalline solids. 19,20

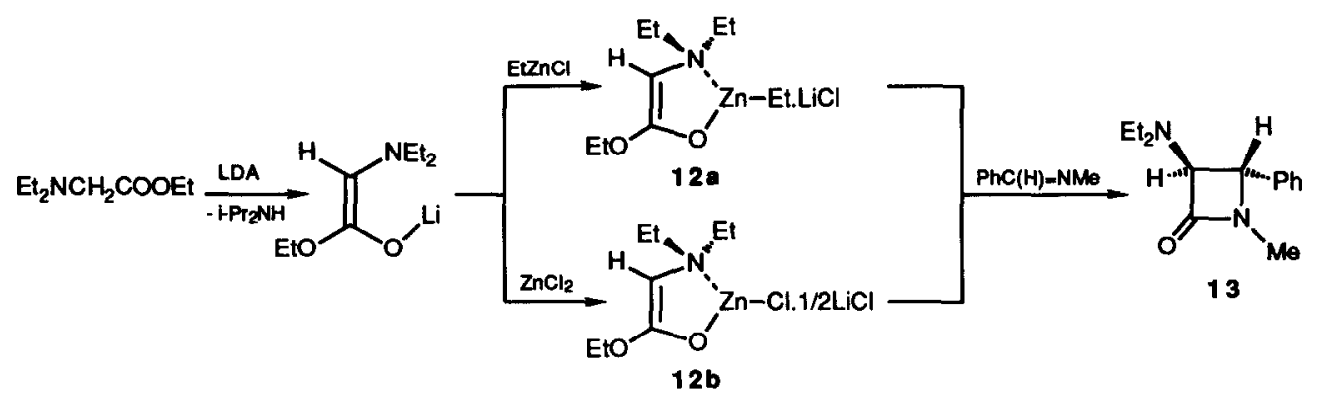

Reaction of both $12 \mathrm{a}$ and $12 \mathrm{~b}$ with $N$-methylbenzaldimine in benzene solution affords a mixture of the cisand trans- $\beta$-lactam 13 in quantitative yield, see eqn. 4 (cis / trans ratio $23: 77$ ). ${ }^{19}$ It appeared soon that it is not necessary to carry out the condensation reaction with a pure and isolated zinc ester enolate. When the reaction is carried out as a simple one-pot synthesis essentially the same products in the same yield are obtained. It is obvious that the lithium- and zinc-ester enolates are not simple monomeric species as schematically depicted in eqn. 4. Therefore a separate study to the synthesis, structure in the solid state and structure in solution of these compounds has been carried out. 20,21

Table I. Synthesis of 1,4-disubstituted-3-diethylamino-2-azetidinones.

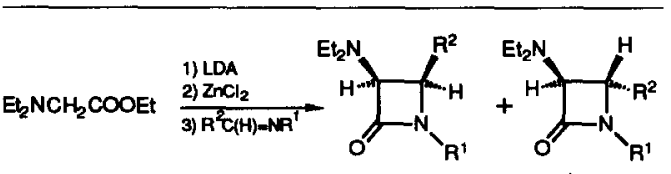

as

trans

\begin{tabular}{cllcr}
\hline Entry & \multicolumn{1}{c}{$\mathbf{R}^{1}$} & $\mathbf{R}^{2}$ & Yield (\%) & cis/trans ratio \\
\hline 1 & $\mathrm{Me}$ & $\mathrm{Ph}$ & 98 & $23: 77$ \\
2 & $\mathrm{CH}_{2} \mathrm{Ph}$ & $\mathrm{Ph}$ & 98 & $6: 94$ \\
3 & $\mathrm{t}^{\mathrm{Bu}}$ & $\mathrm{Ph}$ & 0 & - \\
4 & $\mathrm{SiMe}_{3}\left(\mathrm{HH}^{\mathrm{a}}\right.$ & $\mathrm{Ph}$ & 93 & $<1:>99$ \\
5 & SiMe $_{3}(\mathrm{H})^{\mathrm{a}}$ & $\mathrm{C} \equiv \mathrm{CPh}$ & 98 & $<1:>99$ \\
6 & SiMe $_{3}(\mathrm{H})^{\mathrm{a}}$ & $\mathrm{C} \equiv \mathrm{CSiMe}_{3}$ & 97 & $<1:>99$ \\
\hline a After hydrolysis. & &
\end{tabular}

Table II. Synthesis of 3-N,N-disubstituted-1methyl-4-phenyl-2-azetidinones.

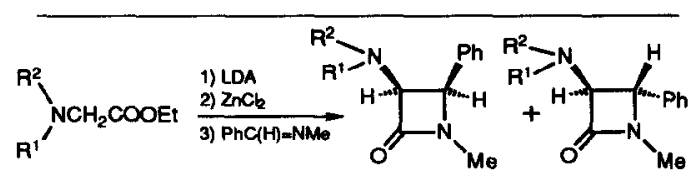

cis

trans

\begin{tabular}{cllcc}
\hline Entry & $\mathbf{R}^{1}$ & $\mathbf{R}^{2}$ & ${\text { Yield }(\%)^{\mathrm{a}}}^{2}$ & cisitrans ratioa \\
\hline 1 & $\mathrm{Me}$ & $\mathrm{Me}$ & $91(80)$ & $47(70): 53(30)$ \\
2 & $-\left(\mathrm{CH}_{2}\right)_{4}^{-}$ & $87(77)$ & $57(73): 43(27)$ \\
3 & $\mathrm{CH}_{2} \mathrm{Ph}^{\mathrm{P}} \mathrm{CH}_{2} \mathrm{Ph}$ & $80(75)$ & $33(50): 67(50)$ \\
4 & $\mathrm{Et}$ & $\mathrm{Et}$ & $98(88)$ & $23(58): 77(42)$ \\
5 & $\mathrm{t}-\mathrm{Bu}$ & $\mathrm{Me}$ & $90(72)$ & $16(25): 84(75)$ \\
6 & $\mathrm{Ph}$ & $\mathrm{Me}$ & $94(80)$ & $2(18): 98(82)$ \\
\hline
\end{tabular}

a Value in bracket corresponding to the reaction in THF.

To extend the scope of this reaction the zinc mediated condensation of $N, N$-diethylglycine ethyl ester with several imines was studied, see Table $1 .{ }^{19}$ Furthermore, to study the influence of different substituents at the nitrogen atom of the glycine ester, these substituents were varied, see Table $\amalg{ }^{22}$ From the first reactions it appears that with increasing size of the substituent present at the imine nitrogen atom the reaction is directed towards the trans-products. That also the size of the substituents at the nitrogen atom of the amino ester plays an important role became evident from the reactions in Table II. When the steric bulk of these substituents increases the formation of trans- $\beta$-lactams is favoured. Also electronic effects influence the cis / trans ratio, e.g., the reaction of the $N, N$-(methyl)phenylglycine ethyl ester, which is the only ester with an electron withdrawing substituent, produces the highest yield in trans- $\beta$-lactam, $c f$. entry 6 in Table II. Furthermore the polarity of the solvent in which the reaction is carried out influences the diastereoselectivity of the reaction. A change of solvent 
from benzene to THF results in an increase of the cis-products, see Table II. Most likely it is the stereochemistry $(\mathrm{E}$ or $\mathrm{Z}$ ) and relative reactivity of the initially formed metal enolate that controls the diastereselectivity of the reaction. 23

To obtain useful 3-amino substituted $\beta$-lactams as intermediates for known and new $\beta$-lactam antibiotics a prerequisite is the presence of an non-functionalized 3- $\mathrm{NH}_{2}$ substituent at the $\beta$-lactam ring to allow further derivatization. Therefore we studied the reaction of the zinc enolates of glycine ethyl ester, containing easily removable groups at the nitrogen atom, with several imines. Unfortunately, reaction of lithium- or zinc enolates of glycine ethyl ester in which the amine function is protected as an amide, e.g. as benzoyl, phthalolyl or 4-phenyl2-oxazolidinone did not show any reactivity towards imines. ${ }^{23}$ However, using alkylsilicon compounds as protecting groups at the nitrogen atom of glycine ethyl ester, excellent yields were obtained in the zinc mediated condensation with imines to $\beta$-lactams, ${ }^{23,24}$ see Table III. After acidic work-up (1M HCl) the 3-NH 2 substituted $\beta$-lactams are obtained. The diastereoselectivity of these reactions is good to excellent (predominantly trans- $\beta$ lactams are formed). Although the reaction of the bis(trimethylsilyl) protected glycine ester gives a somewhat better diastereoselectivity ( $c f$. entries 3 and 6 in Table III) compared to the ester in which the nitrogen atom is part of the 2,2,5,5-tetramethyl-1-aza-2,5-disilacyclopent-1-yl fragment, for practical purposes the latter protective group is favored (more readily available) while, moreover, it is thermally more stable. ${ }^{23}$ In this respect it should be noted that reactions of the lithium enolate of 2,2,5,5-tetramethyl-1-aza-2,5-disilacyclopentane-1-acetic acid ethyl ester with activated imines have been reported earlier and produces (with some exceptions ${ }^{25}$ ) predominantly cis- $\beta$-lactams. $26-28$

Table III. Synthesis of 3-amino-1,4-disubstituted-2-azetidinones.

\begin{tabular}{llllll}
\hline & & & & & \\
\hline
\end{tabular}

\footnotetext{
a After hydrolysis.
}

Enantioselective synthesis of 3-amino-2-azetidinones via the zinc mediated condensation of esters and imines.

It is not only the cis or trans geometry of the four membered ring in $\beta$-lactams that controls the biological activity but also the absolute configuration of the $C^{3}$ and $C^{4}$ ring atoms. Therefore, to obtain useful intermediates for $\beta$-lactam antibiotics a completely enantioselective synthesis (with respect to the $C^{3}$ and $C^{4}$ absolute configuration) is a prerequisite. The zinc mediated condensation of esters with imines to $\beta$-lactams in principle allows two approaches to achieve enantioselective control of the two formed chiral centers: $i$, making use of proper chiral substituents at the ester or, $i$, making use of proper chiral substituents at the imine. Both concepts have been studied recently by our group. 29,30 Some representative examples are given in Table IV.

It appeared that the reactions, which make use of chiral ester enolates, proceed with very poor enantioselectivity, $c f$. cntries 1 and 2 in Table IV. Most probably the chiral information is too far away from the reactive centers. However, when either on the nitrogen- or carbon atom of the imine a proper chiral substituent is present, $\beta$-lactams are formed with a high enantioselectivity, see Table IV. In this respect it should be mentioned that the product obtained in entry 5 , after hydrolysis of the silicon protective group and removal of the chiral substituent at the nitrogen atom of the $\beta$-lactam ring, ${ }^{30}$ is a principal building-block for the known $\beta$-lactam antibiotic aztreonam (see Figure 1). 
Table IV. Synthesis of 3-amino-1,4-disubstituted-2-azetidinones.

\begin{tabular}{|c|c|c|c|c|c|c|c|}
\hline & & & 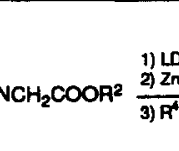 & $\mathrm{R}^{\mathrm{H}}$ & & & \\
\hline Entry & $\mathbf{R}^{2}$ & $\mathbf{R}^{3}, \mathbf{R}^{3}$ & $\mathbf{R}^{1}$ & $\mathbf{R}^{4}$ & Yield (\%) & d.e. $(\%)^{2}$ & e.e. $(\%)^{b}$ \\
\hline 1 & (-) 1-menthyl & Et, Et & $\mathrm{Me}$ & $\mathbf{P h}$ & 84 & $>95$ & 35 \\
\hline 2 & (-) 1-bornyl & Et, Et & $\mathrm{Me}$ & $\mathbf{P h}$ & 81 & $>95$ & 10 \\
\hline 3 & Et - & $-\mathrm{SiMe}_{2}\left(\mathrm{CH}_{2}\right)_{2} \mathrm{Me}_{2} \mathrm{Si}-$ & $(R)-\mathrm{CH}(\mathrm{Me}) \mathrm{Ph}$ & $\mathrm{C}=\mathrm{N}-(R)-\mathrm{CH}(\mathrm{Me}) \mathrm{Ph}$ & 91 & $>98$ & 91 \\
\hline 4 & Et & $-\mathrm{SiMe}_{2}\left(\mathrm{CH}_{2}\right)_{2} \mathrm{Me}_{2} \mathrm{Si}-$ & (R)-CH(Me)Ph & 2-Pyridyl & 98 & $>98$ & $>95$ \\
\hline 5 & Et & $-\mathrm{SiMe}_{2}\left(\mathrm{CH}_{2}\right)_{2} \mathrm{Me}_{2} \mathrm{Si}-$ & (R)-CH(Me)Ph & $\mathrm{Me}$ & 95 & 90 & 80 \\
\hline 6 & Et & $-\mathrm{SiMe}_{2}\left(\mathrm{CH}_{2}\right)_{2} \mathrm{Me}_{2} \mathrm{Si}-$ & 4-MeOPh & (1R)-1,2-O-isopropylideneethyl & 96 & 95 & 90 \\
\hline
\end{tabular}

${ }^{a}$ Trans / cis. ${ }^{b}$ With respect to the $\mathrm{C}^{3}-\mathrm{C}^{4}$ bond formation.

Our latest results in the field of $\beta$-lactam chemistry concerns the enantioselective synthesis making use of imines derived from chiral aminoacid esters. The advantages of this approach are obvious; $i$, a variety of enantiomerically pure aminoacids is readily available from the chiral pool, and $i i$, using imines derived from $\alpha$-aminoacids, $\beta$-lactams are obtained which contain a carboxylic functionality in $\beta$-position with respect to the lactam ring nitrogen atom. As most biologically active bicyclic $\beta$-lactams contain such a $\beta$-carboxylic functionality (see Figure 1) this concept contributes to a more 'atom economic synthesis' because it is not necessary to remove the whole chiral auxiliary for the synthesis of the second ring.

As a model reaction we studied the reaction of silicon protected glycine ethyl ester with the imine derived from $(R)$-2-phenylglycine methyl ester and benzaldehyde. ${ }^{31}$ Surprisingly the imine itself did not show any reactivity in the zinc mediated condensation reaction. However, when the (in situ prepared) $\mathrm{ZnCl}_{2}$ complex of this imine is used under similar conditions $\beta$-lactam 14 was obtained in good yield and high diastereoselectivity (e.e. $>98 \%$, with respect to the $\mathrm{C}^{3}-\mathrm{C}^{4}$ bond formation), see eqn.5. The absolute $(3 S, 4 S)$ stereochemistry was unambiguously proven by an X-ray crystal structure determination of a derivative of 14.31

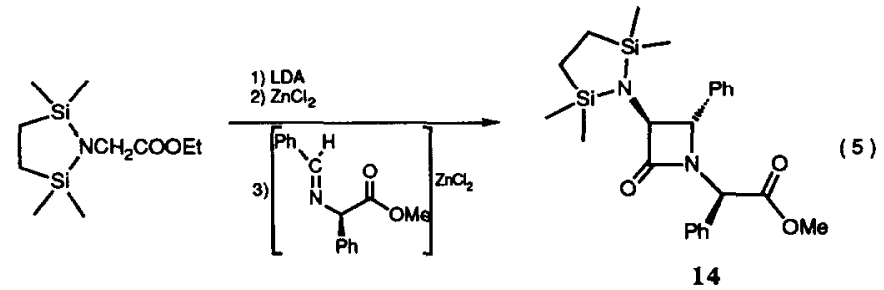

It seems that zinc plays two important roles in this reaction; $i$, it enhances the reactivity of the imine- $C$ atom, most likely as a consequence of its Lewis acid properties, towards $\mathrm{C}-\mathrm{C}$ bond formation, and $i$, the zinc atom in the enolate controls the reactivity and stereoselectivity of the enolate. This topic i.e. the double activation by zinc of both the enolate and the imine in the $\beta$-lactam formation is currently under investigation by our group, ${ }^{31}$ ( $c f$. eqn. 3 for an early example of double activation where it is most likely the $\mathrm{Et}_{2} \mathrm{Zn}$ iminoester complex that is operative in the $\mathrm{C}-\mathrm{C}$ coupling reaction).

\section{Concluding remarks.}

We have shown that the zinc mediated condensation of esters and imines to $\beta$-lactams is a valuable synthetic route to $\beta$-lactams which is complementary and often superior over the well-accepted lithium mediated route. The lithium mediated reaction usually affords $c i s$ - or mixtures of cis- and trans- $\beta$-lactams ${ }^{7-11}$ in moderate yield and, furthermore, only proceeds for reactive imines. The zinc mediated reaction combines high overall yield with high stereoselectivity. Usually trans- $\beta$-lactams are formed but under certain conditions it is possible to control the reaction in such a way (by varying the solvent or co-solvents) that selectively cis- $\beta$-lactams are obtained. Finally, it appeared that some of the reactions can be carried out with a catalytic amount of zinc, ${ }^{23}$ which is an advantage from an environmental standpoint of view. Imines derived from chiral aminoacid esters can be used when the 
'double activation' approach by zinc (cf. eqn.5) is applied.

\section{Acknowledgement}

We kindly acknowledge Dr.F.H. van der Steen, H.L. van Maanen and H. Kleijn for their valuable contributions, Drs. A.P.G. Kieboom and J. Verweij for their suggestions and stimulating discussions. Gist-brocades nv, The Netherlands, is acknowledged for their financial support of our research efforts in the field of $\beta$-lactam chemistry.

\section{References}

1. Staudinger, H. Liebigs Ann. Chem. 1907, 365, 51.

2. The Chemistry of Penicillin; Clarke, H.T.; Johnson, R.; Robinson, R., Ed.; Princeton University Press, 1949.

3. Synthesis of Penicillin Cephalosporin C and Analogs, Manhas, M.S.; Bose, A.K., Ed.; Marcel Dekker: New York, 1969.

4. Mukerjee, A.K.; Singh, A.K. Tetrahedron 1978, 34, 1731.

5. Chemistry and Biology of B-Lactam Antibiotics; Morin, R.B.; Gorman, M., Ed.; Academic Press: New York, 1982, Vol.1-3.

6. Koppel, J.A. Small Ring Heterocycles-Azetidines, B-lactams, Diazetidines and Diaziridines; Hassner A., Wiley: New York, 1982.

7. Brown, M.J. Heterocycles 1989, 29, 2225.

8. Hart, D.J.; Ha, D-C. Chem. Rev, 1989, 89, 1447.

9. Barrett, A.G.M.; Sturgess, M.A. Tetrahedron 1988, 44, 5615.

10. Georg, G.I. Studies in Natural Product Chemistry; Rahman, A-ur, Ed.; Elsevier Science: Amsterdam, 1988, Vol.2.

11. Georg, G.I.; Ravikumar, V.T. The Organic Chemistry of B-Lactams, Georg, G.I., Ed.; VCH Publishers, Inc, New York 1993.

12. Van der Steen, F.H.; Van Koten, G. Tetrahedron 1991, 47, 7503.

13. Gilman, H.; Speeter, M.J. J. Am. Chem. Soc. 1943, 65, 2255.

14. Klerks, J.M.; Jastrzebski, J.T.B.H.; Van Koten, G.; Vrieze, K. J. Organometal Chem. 1982, $224,107$.

15. Van Koten, G.; Jastrzebski, J.T.B.H.; Vrieze, K. J. Organometal. Chem. 1983, $250,49$.

16. Van Vliet, M.R.P.; Van Koten, G.; Buysingh, P.; Jastrzebski, J.T.B.H.; Spek, A.L. Organometallics 1987, $6,537$.

17. Van Vliet, M.R.P.; Jastrzebski, J.T.B.H.; Klaver, W.J.; Goubitz, K.; Van Koten, G. Recl. Trav. Chim. Pays-Bas 1987, 106, 132.

18. Kaupp, M.; Stoll, H.; Preuss, H.; Kaim, W.; Stahl, T.; Van Koten, G.; Wissing, E.; Smeets, W.J.J.; Spek, A.L. J. Amer. Chem. Soc. 1991, 113, 5606.

19. Jastrzebski, J.T.B.H.; Van der Steen, F.H.; Van Koten, G. Recl. Trav. Chim. Pays-Bas 1987, 106, 516.

20. Van der Steen, F.H.; Boersma, J.; Spek, A.L.; Van Koten, G. Organometallics 1991, 10, 2468.

21. Jastrzebski, J.T.B.H.; Van Koten, G.; Van de Mieroop, W.F.Inorg. Chim. Acta. 1988, 142, 169.

22. Van der Steen, F.H.; Kleijn, H.; Jastrzebski, J.T.B.H.; Van Koten, G. Tetrahedron Lett. 1989, 30, 765.

23. Van der Steen, F.H.; Kleijn, H.; Jastrzebski, J.T.B.H.; Van Koten, G. J. Org. Chem. 1991, 56, 5147.

24. Van der Steen, F.H.; Jastrzebski, J.T.B.H.; Van Koten, G. Tetrahedron Lett. 1988, 29, 2467.

25. Andreoli, P.; Billi, L.; Cainelli, G.; Panunzio, M.; Bandini, E.; Martelli, G.; Spunta, G. Tetrahedron 1991 , 47,9061 .

26. Overman, L.E.; Osawa, T. J. Am. Chem. Soc. 1985, 107, 1698.

27. Andreoli, P.; Cainelli, G.; Contento, M.; Giacomini, D.; Martelli, G.; Panunzio, M.Tetrahedron Lett. 1986, $27,1695$.

28. Burnett, D.A.; Hart, D.J.; Liu, J. J. Org. Chem. 1986, 51, 1930.

29. Van der Steen, F.H.; Kleijn, H.; Spek, A.L.; Van Koten, G.J. Chem. Soc., Chem. Commun. 1990, 503.

30. Van der Steen, F.H.; Kleijn, H.; Britovsek, G.J.P.; Jastrzebski, J.T.B.H.; Van Koten, G. J. Org. Chem. $1992,57,3906$.

31. Van Maanen, H.L.; Jastrzebski, J.T.B.H.; Verweij, J.; Kieboom, A.P.G.; Spek, A.L.; Van Koten, G. Tetrahedron Asymmetry, 1993, in press. 